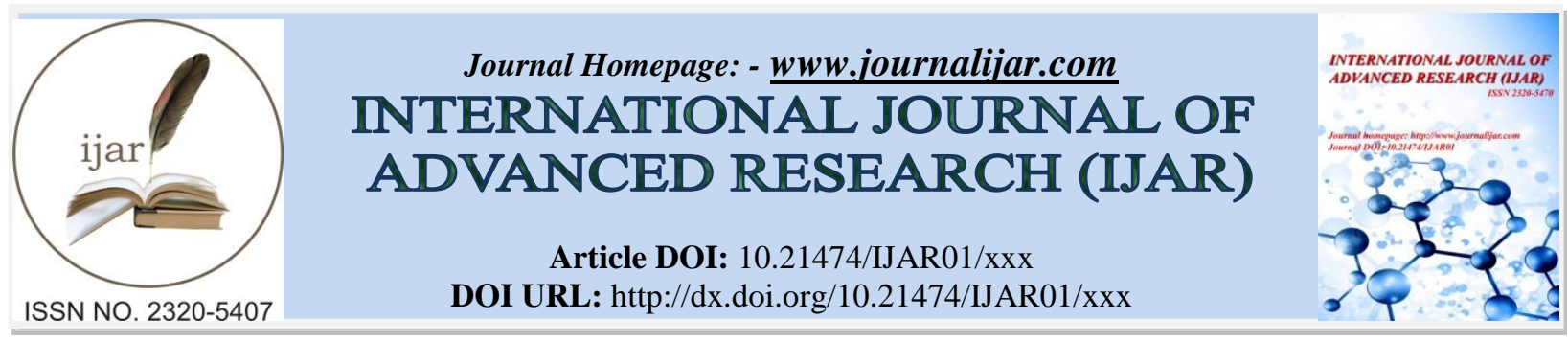

RESEARCH ARTICLE

\title{
STUDY THE PHYSICAL PROPERTIES OF SUDAN NATURAL AND SYNTHETIC ZEOLITES MODIFICATION BY PT ELEMENT.
}

Dr. Ardelshifa Mohammed Elhassan.

King Saudi Arabia Quassim University, college of science and Art Oyun Aljwa, Physic Department.

\section{Manuscript Info}

Manuscript History

Received: $x x x x x x x x x x x x x x x$

Final Accepted: $x x x x x x x x x x x$

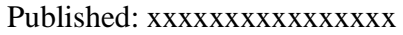

Key words:-

zeolite, DSC, TGA ,TPR and BET.

List of Abbreviations

BET : Brunauer , Emmet, and Teller

TPR : Temperature Program Redecution

TPD : Temperature Program

Determination

TGA : Thermogravimetric Analysis

\section{Abstract}

Zeolites is one of very important elements that for several application in various technologies, Zeolite material, dependence on their extremely high frame work, extended interactive surface, ability to interact with molecules and cations. Show a wide variety of interesting properties which result in remarkable applications in the fields of catalysts, gas separation, selective adsorption and water softening. The natural zeolites are materials with their properties ( that in some cases are even unique) or super than those obtained by synthetic .

The zeolite catalyst loaded with finely dispersed noble metal (Pt) have been used in hydrogenation, hydrocracking, hydroiosmerization and the oxidation of hydrocarbons .

In this study the natural zeolite collected from north of Sudan and prepared it to determination the physical properties. And the other one is Synthetic zeolites (Y). The natural zeolite (scolecite) and synthetic zeolite $(\mathrm{Y})$ are modification by two methods impregnation and ion exchange using ammonium chloride and platinum hydrochloride $\mathrm{H}_{2} \mathrm{PtCl}_{6}$ to upgrade their properties . The study characterized, the natural zeolite ( Scolecite ) and Synthetic zeolites (Y) and their modification using different techniques as follow : Thermal analysis by two methods DSC, TGA ,TPR and measured surface area of zeolite Yby BET. The result show good characterization of two types of zeolites specially after modification with Pt element and it be ready to use in application .

Copy Right, IJAR, 2016,. All rights reserved.

\section{Introduction:-}

\section{Zeolites definition:-}

Zeolites are crystalline aluminosilicates of group IA and IIA elements such as sodium, potassium, magnesium, and calcium. Chemically, they are represented by the empirical formula.

$\mathrm{M}_{2 / \mathrm{n}} \mathrm{O}-\mathrm{Al}_{2} \mathrm{O}_{3}-\mathrm{ySiO} \mathrm{S}_{2}-\mathrm{wH}_{2} \mathrm{O}$

Where $\mathrm{y}$ is 2 to $10, \mathrm{n}$ is the cation valence, and $\mathrm{w}$ represents the number of water molecules contained in the voids of the zeolite. Structurally, zeolites are complex, crystalline inorganic polymers based on an infinitely extending three- dimensional, four- connected framework of $\mathrm{AlO}_{4}$ and $\mathrm{SiO}_{4}$ tetrahedra linked to each other by the sharing of 
oxygen ions. Each $\mathrm{AlO}_{4}$ tetrahedron in the framework bears in Figure (1-2) Pore size distribution of representative adsorbent. A) 5A (CaA) zeolite; B) X or Y zeolite; C) Carbon molecular sieve; D) Activated Carbon; E) porous alumina.

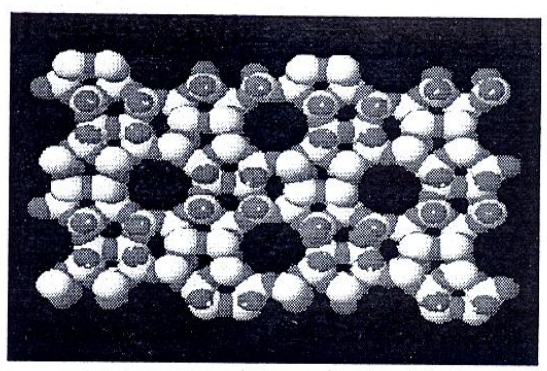

Fig. 1. Zeolite.

A net negative charge which balanced by an extra - framework cation. The framework structure contains channels or interconnected voids; the second provides a system of uniform channels which, in some instances, are onedimensional channel systems. The preferred type has two- or three - dimensional channels to provide rapid intracrystalline diffusion in adsorption and catalytic applications.

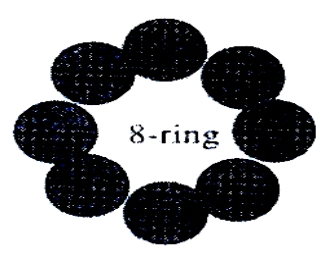

$0.35-0.45 \mathrm{~nm}$ e.g. reolite A

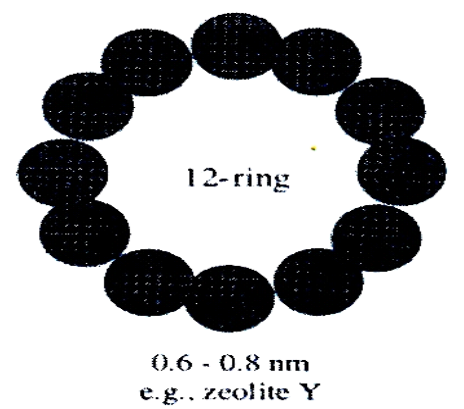

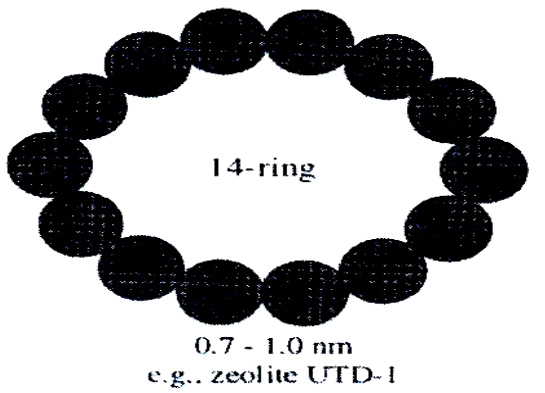

c.g.. zeolite UTD 1

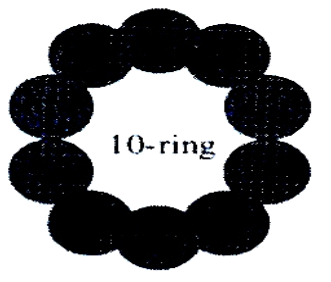

$0.45-0.60 \mathrm{~nm}$ C... ZSSM-5

Figure(2): Typical zeolite pore size illustrated with oxygen packing models.

In most zeolite structures the primary structural units, the $\mathrm{AlO}_{4}$ or $\mathrm{SiO}_{4}$ tetrahedra, are assembled into secondary building units which may be simple polyhedral such as cubes, hexagonal prisms, or Cubo- octahedral. The final framework structure consists of assemblages of the secondary units.

More than 70 novel distinct framework structures of zeolites are known. They exhibit pore size from $0.3-1.0 \mathrm{~nm}$, and pore volumes from about 0.10 to $0.35 \mathrm{cc} / \mathrm{g}$. typical zeolite pore size using oxygen- packing models are shown in figure 2. They include small pore zeolites with eight - ring pore with free diameters of $0.30-0.45 \mathrm{~nm}$, e.g., zeolite A; medium pore zeolites formed by a ten ring, $0.45-0.60 \mathrm{~nm}$ in free diameter, e.g., ZSM-5 large pore zeolites with 12- ring pore, $0.6-0.8 \mathrm{~nm}$, e.g., zeolites $\mathrm{X}$ and $\mathrm{Y}$; and extra large pore zeolites.

The zeolite framework should be viewed as somewhat flexible, with the size and shape in fig (2).

The illustration of the molecular sieve effect, is such that the straight chain molecular normal octane (left) passes through the eight- ring aperture of $5 \mathrm{~A}(\mathrm{Ca} \mathrm{A})$ zeolites; while the branched molecule iso- octane (right) cannot. Zeolite are crystalline aluminosilicate with an open, three dimensional frameworks consisting of tetrahedral $\mathrm{SiO}_{4}{ }^{4-}$ and $\mathrm{AlO}_{4}{ }^{5-}$ units linked through shared oxygen as continuous array. They were discovered by a Swedish mineralogist, constant in the eighteenth country. The $\mathrm{SiO}_{4}{ }^{4-}$ and $\mathrm{AlO}_{4}{ }^{5-}$ units are illustrated in Figure (3). 


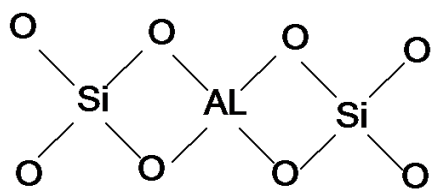

Figure 3:- $\mathrm{SiO}_{4}{ }^{4-}$ and $\mathrm{AlO}_{4}{ }^{5-}$ units in zeolite. Zeolites are micro porous crystals of alkali or alkali earth aluminosilicates with the following stoichiometry:

\section{$\mathrm{Mx} / \mathrm{n}\left(\mathrm{AlO}_{2}\right) \mathbf{x}\left(\mathrm{SiO}_{2}\right) \mathbf{y}, \mathrm{wH}_{2} \mathrm{O}$ :-}

With being the valence of the cation $\mathrm{M}, \mathrm{x}$ and $\mathrm{y}$ integers with $\mathrm{y} / \mathrm{x}$ equal to greater than, and number of molecules of water per cell.

The crystal lattice is built of a three dime national arrangement of tetrahedrons $\left[\mathrm{SiO}_{4}\right]$ and $\left[\mathrm{AlO}_{4}\right]$ connected by their apexes. Theses sequences form polyhadrons that are arranged according to a given symmetry to malice the crystal. The void delimited by the aluminosilicate skeleton is organized into a network of cavities connected by pores of uniform size. The effective pore diameter, variable depending on the type of zeolite, is of the same order of magnitude ( 3 to $10 \breve{A}$ ) as that of most organic molecules. This explains the name "molecular sieve" given to these adsorbents. The $\mathrm{M}$ cations and the water molecules make up the extra-skeletal species. The cation offser the negative charges generated by the aluminum atoms of the skelet on and can be involved in exchanges to adjust adsorption properties.

\section{Zeolites occurring:-}

The zeolites form a large family of alumino silicates which has been studied by mineralogists. For more than 200 years. This is illustrated by the dates discovery of individual members of the group, recorded by break fire crystals are often found lining cavities and oracks in basaltic rocks of volcanic origin. The cavities are considered to be formed by bubbles of fluids in the parent magma, and the zeolite crystals grow as a result of the chemical action on the magma of these fluids or of fluids which have subsequently displaced them.

In general the bulks compositions of the zeolites tend to correlate with those of the parent rock-more aluminous zeolites are associated with rocks deficient in silica and more siliceous zeolites with rocks high in silica. There may be more than one zeolite species present and evidence is sometimes found of slow replacement of one zeolite by another rather than of co crystallization. Zeolite of this volcanic origin is usually dispersed in occurrence and is not there for suitable for industrial purposes.

More massive deposit occurs as very small crystal grains in certain sediments and grade metamorphic rocks. Some of these deposits are extremely large. Aqueous and normally alkaline solutions acting upon volcanic ash deposited in lakes account for much of the zeolitization of this kind phillipsite and clinoptilolite are found in ocean sediments and are again thought to have formed from volcanic debris. Zeolites are sometimes found in arid alkaline soils which may also be rich in salts. Beds rich in zeolites may be hundreds of meters thick; indeed beds of tuff converted largely or in part to zeolites can rich thicknesses of several kilometers. Some deposits can be primarily of on zeolite species and the deposits may contain little else than zeolite .

Zeolites occur in nature and have been known for almost 350 year as aluminosilicate minerals. Example is faujasite, mordenite, offretite, ferierite, erionite and chabazite.

Zeolite are a large class of highly crystalline aluminosilicate materials, defined by a network of linked cavities are pores of molecular dimensions that gives rise to their molecular sieving properties.

Zeolites are also known as molecular sieves. Molecular sieves, zeolites are a class of stable mineral and synthetic crystalline inorganic compounds characterized by the present of an open three dimensional oxide framework structure. This open structure leads to a regular network of uniform pores of specific molecular dimensions. The porous structure cable the zeolite to selectively admit some molecules while excluding those that are too large fit into the pores. This leads to its molecular sieve properties.

Zeolite are a large class of highly crystalline aluminosilicate materials, defined by a network of linked cavities are pores of molecular dimensions that gives rise to their molecular sieving properties .

\section{Zeolites properties:-}

The tetrahedral coordination of the aluminum atoms in the framework generates charge deficiency, which is balanced by cations, which are not an integral part of the framework. Water in zeolites can be removed thermally at around 400 to $500 \mathrm{oC}$ and this leaves the zeolite in its active state when the zeolite is dehydrated, the cations become highly mobile and can be replaced by ionexchange to varying degree depending on the particular zeolite structure and the exchanging cation. The type and number of cation present effects the catalytic, adsorptive and ion-exchange properties of the zeolites. It should be noted that the zeolites available are cations and not anion exchangers and zeolites" Silica-alumina ratio too has a bearing on the above mentioned properties. 
The aluminum containing materials exhibit characteristic zeolite exchange properties and therefore, should be regarded as a molecular sieve and not a zeolite.

Besides, zeolites are also regarded as shape selective catalysts. It is based on the formation of active catalyst sites inside the zeolite pore system, which is very uniform in one or more discrete sizes.

Molecules with dimensions similar to or silently larger them zeolite pores can usually diffuse through the pore structure due to the molecular vibration or breathing of the zeolite pore and the vibration the loaming atoms on the diffusing molecule or perturbations of its structure. Bond cleavage, followed by reconstruction of the bond has been suggested for the diffusion of some in organic materials. In this case, the rate of diffusion controls the rate of reaction rather than by any catalytic phenomenon. Shape selectivity catalysis involves the reactivity of primer, secondary and tertiary carbon atoms, which can be classified into three major classes. They are reactant selectivity, product selectivity and restricted transition state selectivity.

Zeolite is an active catalysts. Hydrogen exchanged zeolites give rise to high acidity selective reactions can occur over zeolites. They can also serve as oxidation or reduction catalysts. It happens often after a metal has been introduced into the framework.

The following is a summary of some catalytic elements of the zeolites:

- $\quad$ defined micro pore system

- $\quad$ crystal size and morphology can be manipulated

- $\quad$ Thermo stability

- $\quad$ Bronsted and Lewis acidity

- $\quad$ Cations at choice

- $\quad$ Dispersion of cations adjustable

- $\quad$ Metal incorporation possible

- Hydrophilicity or hydrophobicity spectrum.

Structures and classification of zeolites:-

There are hundreds of zeolite species occurring naturally or synthetically, and millions more have been hypothetically proposed. Zeolite crystals are constructed from an underlying three-dimensional network of $\mathrm{TO}_{4}$ building black units. Within this network there are loosely bonded exchangeable cations, adsorbent phases and the building black central atom is tetrahedral coordinated with four oxygen atoms. Predominantly, $\mathrm{Si}, \mathrm{Al}$ or $\mathrm{P}$ is the element in the center of the tetrahedral building blocks and is referred as the t-atom. Zeolite networks are constructed by specially accommodating the $\mathrm{To}_{4}$ building blocks by corner sharing the oxygen located at their crystal. Thus, these under lying networks depend directly on the connectivity of $\mathrm{TO}_{4}$, units. Other zeolite crystal components such as cations, adsorbents' phase chemical composition, and observed crystallography properties are irrelevant in the determination of underlying network. There are topological differences between networks in different crystals. The question, what makes zeolites so special when compared to other crystalline inorganic oxide materials, can be a risivedred by mentioning a combination of properties:

The microspores character with uniform pore dimensions, allowing certain hydrocarbon molecules to enter the crystals while rejecting other based on too large a molecular size, the ion-exchange properties which allow to perform all sorts of ion exchange reactions, the ability to develop internal acidity which makes the zeolites interesting materials for catalyzing organic reactions and the high thermal stability of the zeolites.

Zeolites can be classified as natural or synthetic zeolite. Natural zeolites are formed through a chemical reaction between volcanic glass and saline water for over 50,000 years. Most natural zeolites are homogeneous and contaminated. Synthetic zeolites whereas are free of contamination.

Table 1:-Classification of zeolites based on framework topology.-

\begin{tabular}{|l|l|}
\hline Groups & Secondary Buildings Units (SBU) \\
\hline 1 & Single, 4- ring, S4R \\
\hline 2 & Single, 6- ring, S6R \\
\hline 3 & Double, 4- ring,D4R \\
4 & Double, 6- ring,D6R \\
\hline 5 & Complex 4-1, $\mathrm{T}_{5} \mathrm{O}_{10}$ unit \\
\hline 6 & Complex 5-1, $\mathrm{T}_{8} \mathrm{O}_{16}$ unit \\
\hline 7 & Complex 4-4-1, $\mathrm{T}_{10} \mathrm{O}_{20}$ unit \\
\hline
\end{tabular}


The relatively simple configurations resulting from their linkages are called secondary building units. Some of the more common secondary building units found in zeolite framework is illustrated in figure (4).
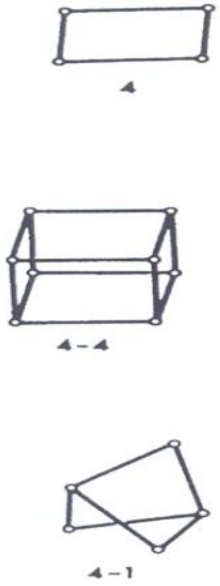
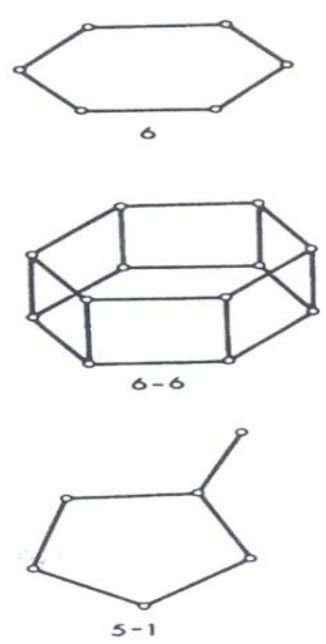
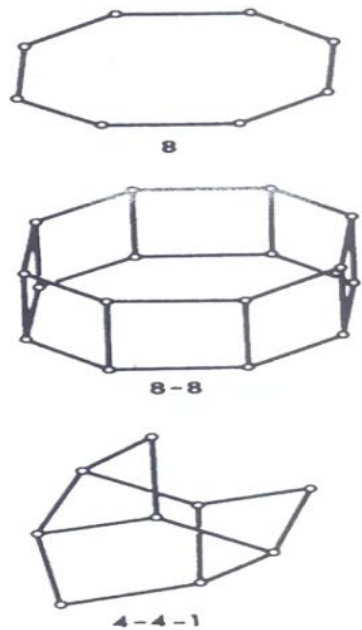

Figure 4.2. Secondary building units of zeolite framework

Figure (4) Secondary building units of zeolite framework:-

There are over 45 known different framework topologies for natural zeolites, and nearly 150 synthetic type have been reported.

The remaining 113 zeolites span arranges pore widths which coincides with the range of dimensions of a very large number of molecules. It is furthermore seen from Fig. 4 that zeolite with eight ten and 12-membered ring pores for which, respectively, the terms small-pore, medium-pore and large-pore zeolites are customary, strongly predominate with a total of $\mathrm{LOH}$ structures, whereas the super-large-pore materials with pores formed by more than $12 \mathrm{TO}_{4}$-tetrahedra and materials with pores formed by an add number of $\mathrm{TO}_{4}$-tetrahedra are still scant.

One advantage of zeolites is their regular intracrystalline pore system, formed a three dimensional network of corner sharing TO4-tetrahedra $\mathrm{T}=\mathrm{Si}, \mathrm{Al}$ ). This create the high surface area of zeolites, with over 9970 (depending on the crystalline size) inside the bulk. The space of these molecular scale microspores, which depends upon the precise architecture, is responsible for the shape selective properties of the zeolitic catalysts. Until now more than 30 different natural and over 50 synthetic zeolite structures are known.

The availability of new zeolite structures yearly increase, reading the impressive number of 179 different framework types known today. Each of them is characterized by a peculiar porous structure and may differ from the others in terms of free dimension of the pore openings, dimensionality of the pore system (1D,2D or 3D), presence or absence of cages. Since the diffusivity and reactivity of the organic species involved in a catalytic process i.e. reactants, intermediates, products) strongly depend on their interaction with the inorganic framework, it is clear that a deeper in sight in to these phenomena is necessary not only for an accurate interpretation of the catalytic data but even for prediction. The behavior of a given zeolite .

Today, these and other zeolite structures are of great in test in catalysis, yet their naturally occurring forms are of limited value, because (I) they almost always contain undesired impurity phases, (ii) their chemical composition varies from one deposit to another and even from one stratum to another in the same deposit, and (iii) nature did not optimize their properties for catalytic applications.

It was only with the advent of synthetic zeolites from catalyst that this class of porous material began to play a role in catalysis.

The terms zeolites, micro porous material and molecular sieve are there form of ten used as synonyms indicating that the regular array of micro pores with well-defined dimensions is the unifying principle which renders this wealth of materials attractive for catalysis (and other application).

\section{Applications:-}

Zeolites one crystalline material with regular structures consisting of molecular sized pores and channels. These crystals are widely used in the field of adsorption, ion-exchange, heterogeneous catalysis (basically all gasoline 
production employs zeolite catalysts), as well as health applications, sensors energy conversion. The dimensions of zeolites channels and their ability to adsorb gases and water have made zeolite molecular sieves suitable for a number of applications such as in the areas of refinery fuel processing, production of chemicals and environmental pollution control.

A wide variety of industrial applications of zeolites, mainly catalysis and separations, exist. Development of the methanol to gasoline (MTG) process by Mobil in the 1970's ( increased gasoline yield from each barrel of crude oil by 50 percent and improved octane number) and development of methanol to olefins (MTO) process by UOP/ hydro in 1996 (UOP/ hydro 2007) surred petrochemical zeolite applications. Heterogeneous catalysts have an edge over liquid - phase processes waste minimization, wide range of possible process operating conditions, and case of product separation are some advantages.

However, solid- acid catalysts cannot replace all industrial homogeneous catalysts. Difficulties in reactant and product diffusion to and from the zeolite surface in the absence of solvent are major obstacle.

There are three main zeolites industrial application: catalysis, gas separation and ion exchange (Lentech 2007). A more detailed description is available elsewhere .

Porous inorganic materials such as zeolites and zeolite like crystalline molecular sieves are of great interest because of their range of commercial applications such as catalysis, adsorption/separation, and ion exchange, the term zeolite refers to the specific class of aluminosilicate molecular sieves, although the term is frequently used more loosely to describe compounds other than aluminosilicates that have frameworks similar to known zeolites.

\section{Physical and Chemical properties of zeolites:-}

Before a zeolite can be used for a certain application an it's necessary to characterize this zeolite, to see if it has the desired properties for that application. If not, another synthesis method should be used or the zeolite must be modified, to meet the specific cations. Zeolite synthesis; modification, characterization and application .

Of course not all zeolite properties are of the same importance every application. This aspect is illustrated in fig (4) in which is indicated, which characteristics are of special importance for the main application of three different zeolite A in detergents particle size and morphology are extremely important while acidity and stability play a minor role.

These characterizations, however, are just of crucial importance for the application of zeolite y in cracking catalysts for this reason we will discuss the different characterization methods in relation to the application for which the specific property is important . 


\begin{tabular}{|c|c|c|c|}
\hline Important & \multicolumn{3}{|c|}{ Type of Zeolite } \\
\hline characteristic & Zeolite A & Zeolite y & ZSM-5 \\
\hline \multicolumn{4}{|l|}{ Structure defects } \\
\hline \multicolumn{4}{|l|}{ Pore-Size } \\
\hline \multicolumn{4}{|l|}{ Chemical composition } \\
\hline \multicolumn{4}{|l|}{ Framework Si/Al Ratio } \\
\hline \multicolumn{4}{|l|}{ Acidity } \\
\hline \multicolumn{4}{|l|}{ Stability } \\
\hline \multicolumn{4}{|l|}{ Morphology particle size } \\
\hline Important application & $\begin{array}{l}\text { Absorbent } \\
\text { ion } \\
\text { exchanger } \\
\text { in } \\
\text { detergents }\end{array}$ & $\begin{array}{c}\text { Crakcing } \\
\text { catalyst }\end{array}$ & Shape selective ctalyst \\
\hline
\end{tabular}

Fig. (4) Most important characteristics for three well-known zeolites and their major .

Table 2:- The physical and chemical properties of zeolites as the framework $\mathrm{Si} / \mathrm{Al}$ ratio is increased:-

\begin{tabular}{|l|l|}
\hline \multicolumn{1}{|c|}{$\mathrm{SiO}_{2} / \mathrm{Al}_{2} \mathrm{O}_{3}$} & From $0-5$ infinity \\
\hline Stability & From $700^{\circ} \mathrm{C}$ to $1300^{\circ} \mathrm{C}$ \\
\hline Surface selectivity & From hydrophilic to hydrophobic \\
\hline Acid site density & Decreasing \\
\hline Acid strength per site & Increasing \\
\hline Cation concentration & Decreasing \\
\hline structure & From $4-6-$ and $8-$ membered rings to 5-membered ring \\
\hline
\end{tabular}

The reactivity and the selectivity of molecular sieve zeolites as catalysts are determined by active sites. The active sites are provided by an imbalance in change between the silicon and the aluminum ions in the framework. Each aluminum atom contained within the framework structure induces a potential active acid site. The replacement of $\mathrm{SiO}_{4}$ teterahedra by the $\left(\mathrm{AlO}_{4}\right)^{-1}$ teterahedra in the zeolite framework causes excess negative charges and protons are needed to neutralize them. Compensation the negative charge by an associated cations, e.g. $\mathrm{H}^{+}, \mathrm{Na}^{+}, \mathrm{K}^{+}, \mathrm{Ca}^{2+}, \mathrm{NH}_{4}$ generate the acid sites.

If the charge compensating cation associated with the tetrahedral aluminum is hydrogen, the zeolite surface obtains the capacity to act as a proton donor and therefore can serve as abronested acid that is proton - donor acidity, 
When hydrogen for zeolite is heated to a temperature than $550^{\circ} \mathrm{C}$, lewis acid site and water occur. Lewis acidity is electron acceptor acidity. One Lewis acid site is formed from two Bronsted acid sites. Formation of lewis acid site. If transition metals are introduced into the zeolite by conventional ion exchange techniques, a third type of active site can be generated.

\section{Material and methods:-}

Natural zeolite collected from north of the Sudan. The zeolite crystals separated from rock sample were washed, dried, crushed and sieved to obtain fine powder. The powder was refluxed with doubly distilled water to remove soluble impurities. It was then decanted and dried in an oven for two hours. The fine powder of natural zeolite is used for further modification upgrade their properties. Various techniques (impregnation, ion exchange) are available to introduce metal-support integration is weaker and large metal particles are obtained which can affect secondary reaction, namely those which are structure sensitive an example being hydrogenoloysis.

On other hand, the ion exchange technique normally brings about a strong metal -support interaction. The physical properties were characterized by the Analysis used, the thermal analysis , (DSC,TPD ,TPR ), surface area BET , scan electron, atomic absorption were done also. All this techniques was implicated to synthetic zeolite Y also .

\section{Catalyst Preparation:-}

Various techniques are available to introduce metal-support integration is weaker and large metal particles are obtained which can affect secondary reaction, namely those which are structure sensitive an example being hydrogenoloysis.

On other hand, the ion exchange technique normally brings about a strong metal -support interaction.

Impregnation:-

Impregnation is the simplest and most direct method. The objective is to fill the pores with solution of a metal salt of sufficient concentration to give the loading.

The impregnation method involves three steps:

- With excess of solution. The support is placed on a screen and dipped into an excess quantity of solution for the time necessary for total impregnation the solid is then drained and dried

- With repeated application of solution. A more precision control is achieved by this technique termed dry impregnation or impregnation to incipient wetness. The support is contacted with a solution of appropriate concentration, corresponding in quantity to the total known pore volume or slightly less. The catalysis is kept in motion in rotated cylinder or a drum, and sprinkled as required with a solution of salt by sprayer.

For both techniques the main operating variable is the temperature which affects both the precursor solubility and the solution viscosity and as a consequence, the wetting time.

Ion Exchange Method:-

Ion Exchange is the reversible interchange of ions between a solid and a liquid in which there is no permanent change in the structure of the solid that is the ion-exchange material usually contacting the zeolite with a salt solution of different cation performs ion exchange reaction one type of cation is replaced with another.

The ion exchange process may be represented as follows

$\mathrm{Z}_{\mathrm{A}} \mathrm{B}_{(\mathrm{Z})}^{\mathrm{ZB}}+\mathrm{ZB} \mathrm{A}_{(\mathrm{S})}^{\mathrm{ZA}} \leftrightarrow \mathrm{ZAB}_{(\mathrm{S})}^{\mathrm{ZB}} \mathrm{ZBA}^{\mathrm{ZA}}$

Where $\mathrm{ZA}, \mathrm{ZB}$ are the charges of the exchange cation $\mathrm{A}$ and $\mathrm{B}$, the subscripts $\mathrm{Z}$ and $\mathrm{s}$ refer to the zeolite and solution, respectively the ion exchange behavior of the zeolite depends upon:

- $\quad$ The nature of the cation specie, the cation size both anhydrous and hydrated and the cation charge

- The charge temperature

- The concentration of the cation specious in solution

- $\quad$ The anion specious associated with the cation in the solution

- Solvent

- The structure characteristics of the particular zeolite.

Plating method :

This method was done by used the plating instrument to preparing zeolites to be ready to use in catalysis application

\section{Commercial ( $\mathrm{Na}$ Y) Zeolite and Scolecite preparation:-}

The NaY zeolite was supplied by union carbide corporation with an atomic ratio of $\mathrm{Si} / \mathrm{Al}=2.36$ and was highly crystalline.

The acid form of this zeolite was obtained by ion exchange $200 \mathrm{~g}$ zeolite $\mathrm{y}$ are mixed careful, continue the mixed from period to period with $\mathrm{NH}_{4}$ solution $\mathrm{NH}_{4}<99 \%$ ) with aqueous ammonia access aqueous ammonia was added slowly to the $200 \mathrm{~g}$ of Zeolite $(\mathrm{NaY})$ with vigorous stirring at $70^{\circ} \mathrm{C}$ then the $\mathrm{PH}$ was increased up to 7 by drop wise addition of aqueous ammonia with stirring after stirring at $70^{\circ} \mathrm{C}$ for $24 \mathrm{~h}$, the precipitated gel (H/Y) was filtrated 
and washed thoroughly by distillation water until the PH becomes less than 7 , dried at $110^{\circ} \mathrm{C}$ for $12 \mathrm{~h}$, and subsequent calcination in air atmosphere at $530^{\circ} \mathrm{c}$ for $4 \mathrm{~h}$, resulting in acid form $(\mathrm{H} / \mathrm{Y})$.

The supported metallic catalyst was prepared by incipient wetness impregnation using 0.35 mass $\%$ metal from $\mathrm{H}_{2}$ $\mathrm{PtCl}_{6}$ added $200 \mathrm{ml}$ from $\mathrm{H}_{2} \mathrm{PtCl}_{6}$ solution to the zeolite $\mathrm{H} / \mathrm{Y}$, heated in temperature $110{ }^{\circ} \mathrm{C} \mathrm{min}^{-1}$ for 12 hours in dynamic air flow at a rate of $50 \mathrm{~cm}^{3} \mathrm{~min}^{-1}$ and calcinated in $530{ }^{\circ} \mathrm{C}$ for 4 hours.

$\mathrm{The} \mathrm{Pt} / \mathrm{H} / \mathrm{Y}$ and $\mathrm{H} / \mathrm{Y}$ the properties determined by instrument surface area BET and, thermal analysis (DSC,TPD ,TPR were done also.

2- All the experiments before was do to the natural zeolite scolecite and the characteristics were studied too by Thermal Analysis by TPR and TPD, , DSC, and surface area. The Zeolite were characterized by Thermo analytical measurement were carried out on a perkin Elmer Ta A-7 instrument and on a perkin Elmer Data -17000 instrument with $1 \mathrm{~m} \%$ of purity the acid properties of $\mathrm{pt} / \mathrm{H} / \mathrm{Y}$ and $\mathrm{Pt} / \mathrm{H} / \mathrm{Scolesite}$ zeolite were investigated to upgrading the product properties.

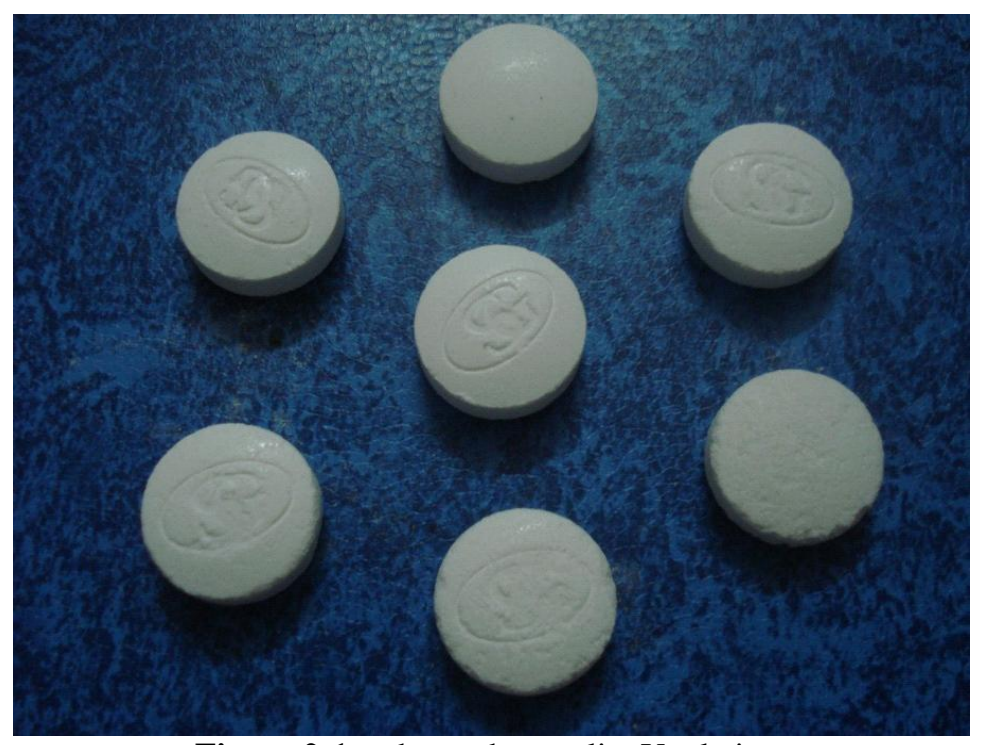

Figure 2-1:a shows the zeolite $\mathrm{Y}$ plating.

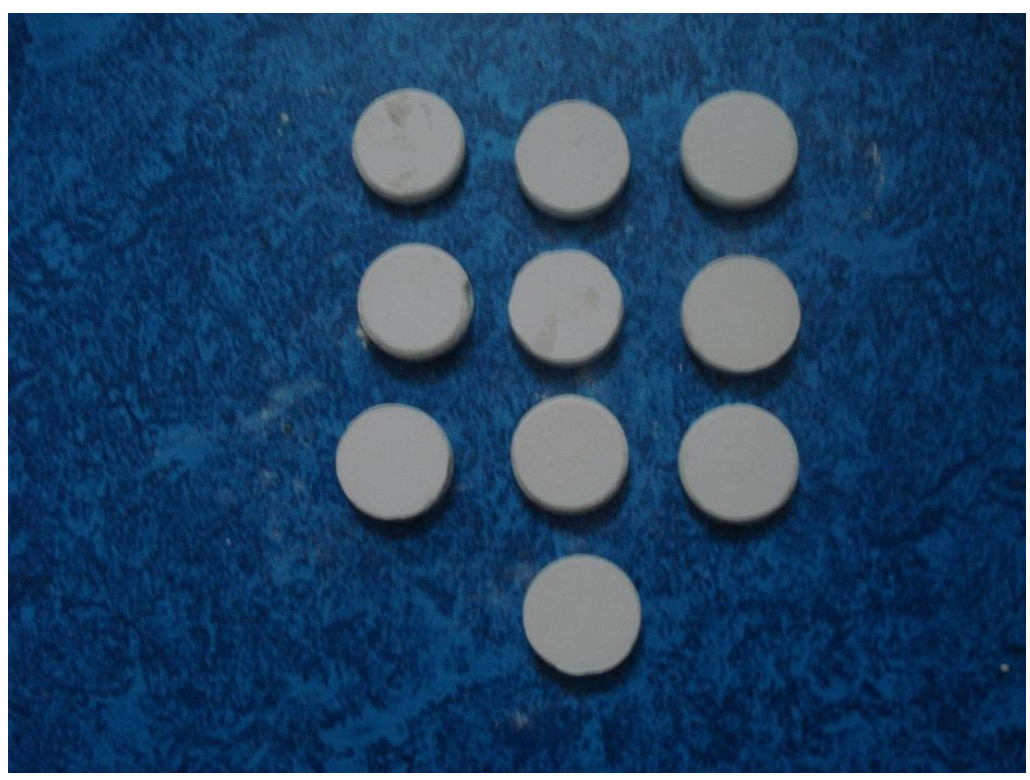

Figure 2-2:- b shows zeolite scolecite plating.

\section{Characterization:-}

In general, the characterization of a zeolite has to provide information about, the ability to sorb and retain molecules and the ability to chemically convert these molecules. Information on the structural, chemical and catalytic 
characteristics of zeolites is essential for deriving relations between their chemical and physicochemical properties on the one side and the sorptive and catalytic properties on the other side. Such relations are of high importance, as they allow the rational development of sorbents, catalyst and advanced structural materials. In this study, the zeolite was synthesized from rice husk ash and the main uses are as cation exchangers and sorbent, thus only characterizations with respect to these applications are being dealt with in depth. There are many characterization techniques but the important physical ones in this study are studied. Each of the characterization techniques will be described below.

Analysis by temperature programmed reduction ( TPR ):-

( TPR ) measurement were carried out in amicromeritics ( chemisorb 2705) system provided by a thermal conductivity detector ( T C D )

to monitor the $\mathrm{H}_{2}$ consumption. A quarter $\mathrm{U}$-tube was packed with a small amount ( 0 -1g) of calcined sample. Before the measurement, the sample was gradually heated up to $200{ }^{0} \mathrm{C}$ at $10{ }^{0} \mathrm{C} / \mathrm{min}$, head for $1 \mathrm{~h}$ , and then cooled down to $25{ }^{\circ} \mathrm{C}$ under argon atmosphere. Afterwards, the reduction carrier gas of $5 \% \mathrm{H}_{2} /$ $\mathrm{N}_{2}$ was flowed through the reactor at rate of $40 \mathrm{ml} / \mathrm{min}$. The TPR was taken by heating the reactor up $1000 \mathrm{c}$ at a constant rate of $10{ }^{\circ} \mathrm{C} / \mathrm{min}$. The water product was trapped by passing the effluent gas plus liquid nitrogen ${ }^{130}$.

Thermal Analysis of Zeolites Y (Synthesis) and Scolecite (Natural):-

Zeolite are framework aluminosilicates with open channels containing molecular water and extra framework cautions. Their distinctive crystal structures endow them with high cation - exchange capacities and molecular sieve capabilities, which are widely applied in water soften, catalysis and waste water treatment. Thermodynamic date are essential to determine the stability of zeolites and evaluate their Para genesis.

Reversible dehydration of intracrystalline water in zeolites is an important consideration for assessing their stability particularly at elevated temperatures and pressures.

In this study, we have directly measured heat or temperature of zeolites by simultaneous differential scanning calorimetric (DSC), and thermo gravimetric analysis (TGA) system and used the TPD, TPR also. The temperature dependence of enthalpies of hydration $\mathrm{H}_{\text {hyd }}$ in zeolite and scolecite. The temperature dependence of $\mathrm{H}$ hydro provides and alternative mean of assessing Cp.r.

In addition, the stability of zeolites with respect to other a luminosilicates is dependent on their hydration state as hydrated zeolites are often stable at earth surface conditions with respect to dense a luminosilicate assemblages and free water, but their dehydration are not. In fact, accurate prediction of the partial dehydration of zeolites can be key to understanding their stability in geologic environments - Dehydration also has a dramatic effect on the ionexchange properties of zeolites.

Hydrothermal systems often produce zeolites as well with complex Para geneses caused by overprinting of digenetic and metamorphic occurrences. Zeolite stability is sensitive function of pressure, temperature and fluid composition, making them useful indicators of the physical and chemical conditions associated with petroleum resources, geothermal resources and basalt- hosted one deposits in earth's crust. Zeolites and associated authigenic day minerals can significantly reduce the porosity and permeability of hydrocarbon reservoir rocks, and their presence is often regarded as an economic basement of exploration for oil and gas.

In addition, they are frequently considered as passive barriers in radioactive waste repositories both as sorptive barriers radionuclide migration and consumption of thermal energy .

The response of zeolites to changes in temperature and water vapor pressure is a very important aspect of their behavior and structural change. Detailed studies of the structural effects accompanying dehydration processes allow evaluation of the changes in environmental conditions that ultimately lead to structural modification or breakdown.

divided zeolites into three categories according to their thermal stabilities. Those with: -

1. Reverse rearrangement of the extra framework cations and residual water molecules.

2. complete or nearly complete reversible dehydration accompanied by a large distortion of the framework and significant decrease in unit-cell volume and

3. irreversible dehydration accompanied by irreversible change in the framework.

Equilibrium between a zeolite and water vapor can be represented by a reaction of the form.

$\mathrm{ZnH}_{2} \mathrm{O}=\mathrm{Z}+\mathrm{nH}_{2} \mathrm{O}$ vapor, where $\mathrm{Z} \cdot \mathrm{nH}_{2} \mathrm{O}$ and $\mathrm{Z}$ are homologous hydrated (water sites occupied) and dehydrated (water sites vacant) components of a zeolite and is the number of moles of $\mathrm{H}_{2} \mathrm{O}$ in the fully hydrated zeolite. The one approach to determined thermal of zeolite is transposed temperature drop calorimetry in which $\mathrm{H}_{\mathrm{r}}$ is determined via thermochemical cycle involving dehydration of the zeolite at high temperatures (usually and heat content of the hydrated 973) zeolite and water.

Determination of the temperature dependence of $\mathrm{Cp}$ of hydrous mineral at super ambient conditions, particularly those that dehydrate continuously with temperature such as zeolite presents considerable experiment obstacles. 
Calorimetric measurements of $\mathrm{Cp}$ by adiabatic, drop, or differential scanning Calorimetry (DSC) on these materials will inevitably include contribution not only from $\mathrm{Cp}$ but also the heat of dehydration.

\section{Calorimetric technique:-}

All the calorimetric measurement were performed on the net zseh STA49C Jupiter simultaneous thermal analysis system at of Florida. A schematic depication this system is shown in fig 1-3.

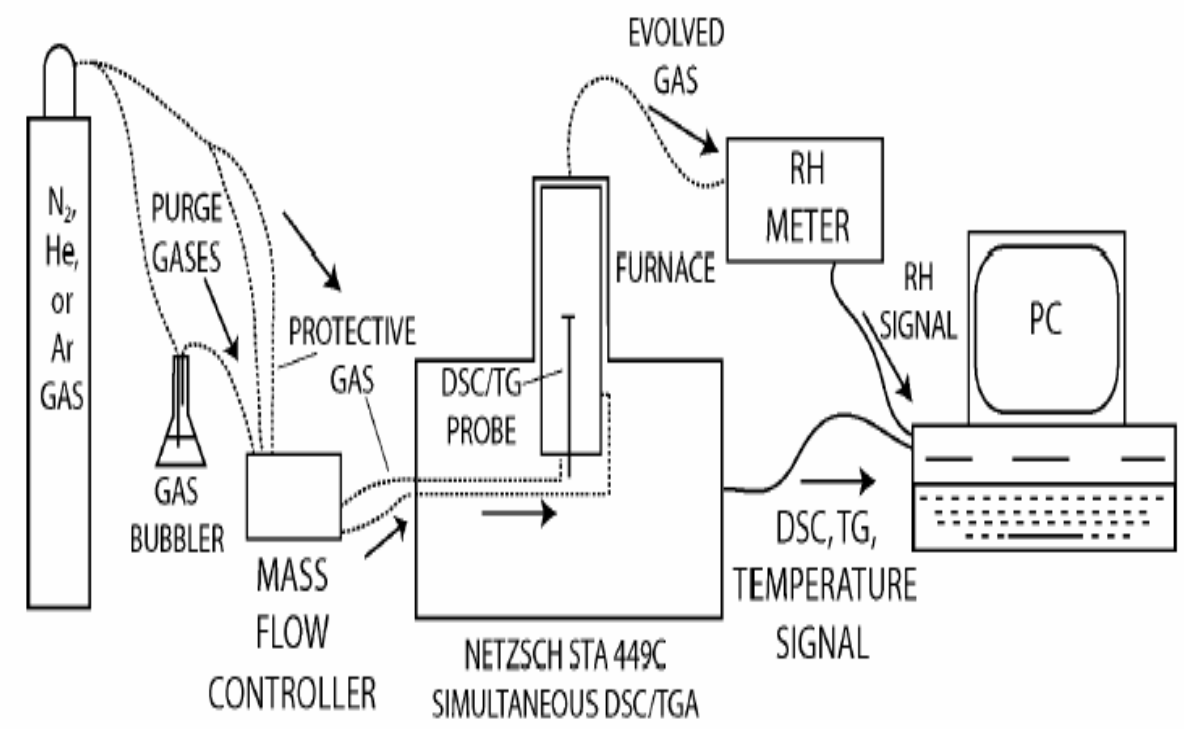

Figure 2-3:- Schematic representation of the simultaneous DSC/TGA system. Dashed

Curves represent gas lines; solid curves represent data transfer cables between the instruments and the computer.

The core component is a vacuum - tight, liquid nitrogen cooled furnace enclosing a sample carrier housing and electrode for measurement of temperature differences between the sample and reference pan, generating a heat flux DSC signal and thermo gravimetric analysis. With respect to setup is that the DSC and TGA signals are signal tobe interpreted directly in terms of water loss or gain to the sample as measured by TGA. The temperature range for the furnace is 120 to $1050 \mathrm{~K}$; temperature can be maintained within this range to a precision of better than $1 \mathrm{k}$ and fro dynamic analysis can be run at controlled heating or cooling rates of up to 50k/minute. Samples as large as $5 \mathrm{gr}$ and as small as $1 \mathrm{mg}$ can be investigated, although sample sizes of the order of a few 10's of $\mathrm{mg}$ are optimal. Mass changes as small as 0.1 can be detected. Calorimetric precision varies with experimental conditions and the amount of heat involved; instrument specification call $\mathrm{Cp}$ precision on the order of $2,5 \%$ and heat of reaction precision on the order of $3 \%$.

Temperature and caloric calibration is performed by measuring the melting temperatures and heats of fusion high purity metal standards and Cp of sapphire disks. Temperature, DSC, and TGA a signals are sent via data analysis.

Experimental conditions can be controlled with respect to not only temperature but also pressure. Experiments can be run under closed system conditions at total pressures ranging from atmospheric to vacuums of 10-4 torr, although typical operation involves a following gas atmosphere at atmospheric pressure - gas composition and flow rate are controlled externally via mass flow controllers, gases used in the experiments are ultra high purity $\mathrm{He}$ (for sub ambient temperatures) and $\mathrm{N}_{2}$ (for $\mathrm{C}_{\mathrm{p}}$ measurement and measurements under controlled humidity conditions). Humidity is a constant temperature, with water vapor pressure $\left(\mathrm{PH}_{2} \mathrm{O}\right)$ varied by mixing $\mathrm{H}_{2} \mathrm{O}$ - saturated and dry $\mathrm{N}_{2}$ gas in proportions. Humidity on the out and recorded by a sable systems RH-100 flow - through view point/relative humidity analyzer (1\% accuracy in $\mathrm{PH}_{2} \mathrm{O}$ down to $1 \mathrm{pa}$ ).

\section{Heat Capacity Measurements:-}

The heat capacities of hydrated and dehydrated scolecite and zeolite $\mathrm{Y}$ were also determined by DSC also on the simultaneous DSC-TGA system. Each experiment consisted of four separate runs: 1) determination of ack ground and baseline by measurement of an empty crucible; 2) DSC measurement of a standard (sapphire); 3) scanning heating of hydrated

scolecite and 4) scanning heating of dehydrated analcime. A sample of approximately $1.0 \mathrm{mg}$ was packed into a covered Pt-Rh crucible before step 3 and kept to the end of the experiment. Data were collected in the range of 298 to $873 \mathrm{~K}$ at a scanning rate of $1519 \mathrm{~K} / \mathrm{min}$. A purge of dry $\mathrm{N} 2$ was used during the experiment to keep the relative humid it below $1 \%$, and the gas flow was maintained at $\sim 30 \mathrm{ml} / \mathrm{min}$ using mass flow controllers. 
The furnace was heated to $873 \mathrm{~K}$ in each run and then cooled back to room temperature by liquid N2 before the next step. During heating, hydrated zeolite lost mass with increasing temperature and finally became completely dehydrated. The resulting dehydrated analcime was kept in an environment of dry N2 to avoid rehydration during cooling to room temperature and then measured by scanning heating again. Heat capacity of the sample as a function of temperature was calculated by

$$
C_{p}=\frac{m_{s t d}}{m_{s}} \times \frac{D S C_{s}-D S C b}{D S C_{s t d}-D S C_{b}} \times C_{p, s t d}
$$

where $\mathrm{ms}$ is the mass of sample, mstd is the mass of standard $(27.314 \mathrm{mg})$, DSCs, DSCstd and DSC b are for sample, standard and baseline respectively. Triplicate calorimetric measurements were conducted and averaged. Based on previous measurements in this lab the precision was taken to be $1 \%$ of average value.

\section{Results and Discussion:-}

In this study the characterization of zeolite Y synthetics and type of natural zeolite from the Sudan areas is collected (zeolite scolecite ) indicated all of their properties, I choice zeolite scolecite and zeolite $\mathrm{Y}$ to determine the characterization shown in figure bellow.

\section{Thermal analysis of scolecite:-}

TPR and TPD analysis:-

Figures (2-4), (2-5 and (2-6) below show the tepereture reduction and thermal determination programs of zeolite scolecite, and scolecite after treatment with ammonia and after treatment with platinum hydrochloride $\left(\mathrm{H}_{2} \mathrm{PtCl}{ }_{6}\right)$. The figures illustrated increase in zeolite stability temperature after treatment with ammonia and platinum.

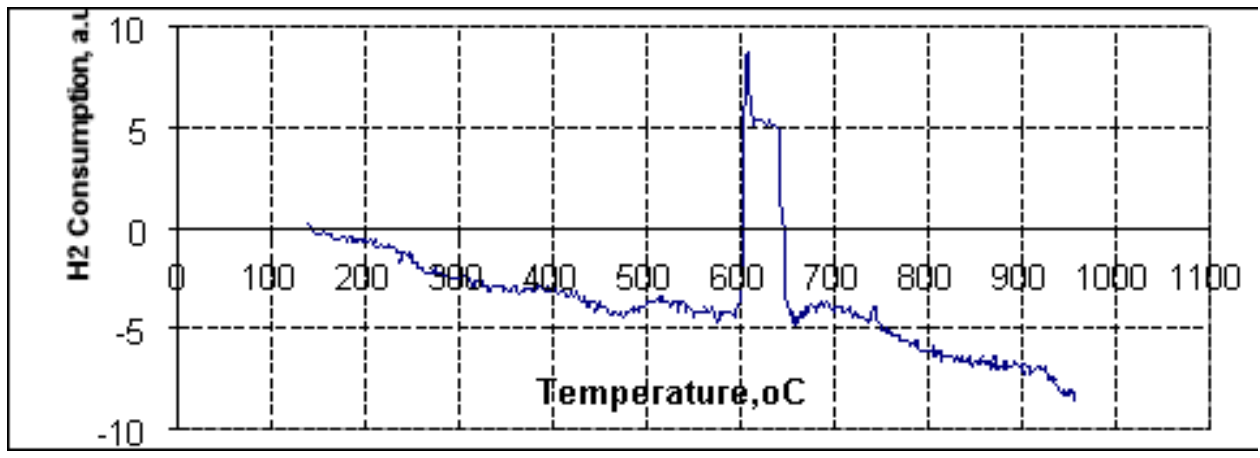

Figure (2-4) TPR/SCOLECITE

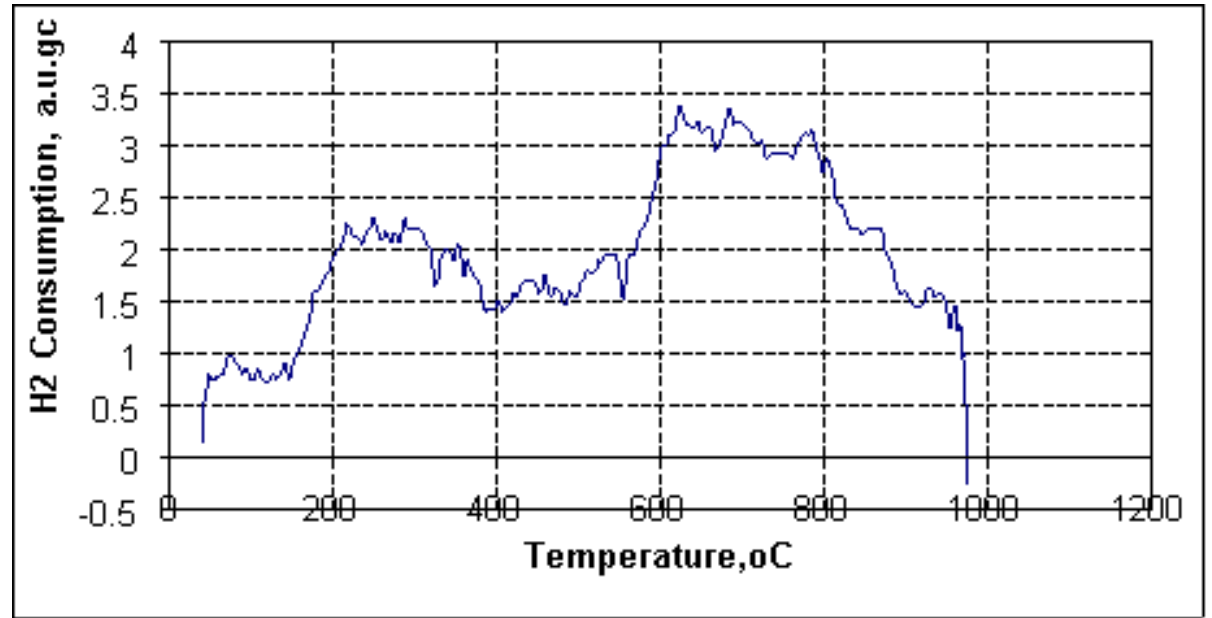

figure(2-5) TPR of H/SCOLECITE 


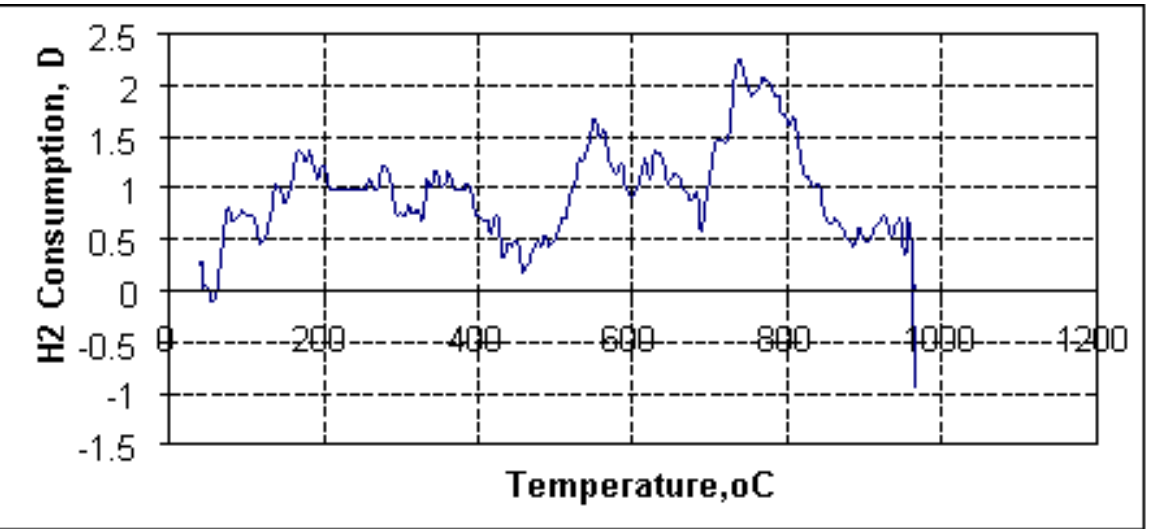

\section{figure (2-6) TPR of Pt/ H/SCOLECITE}

\section{3-3-5- DSC and TGA analysis of scolecite zeolite:-}

Figures (2-7), (2-8) and (2-9) show the temperature analysis of scolecite zeolite, scolecite treated with ammonia (H/ scolecite) and scolecite treated with platinum hydrochloride( $\mathrm{Pt} / \mathrm{H} / \mathrm{scolecite})$ by DSC and TGA analysis.

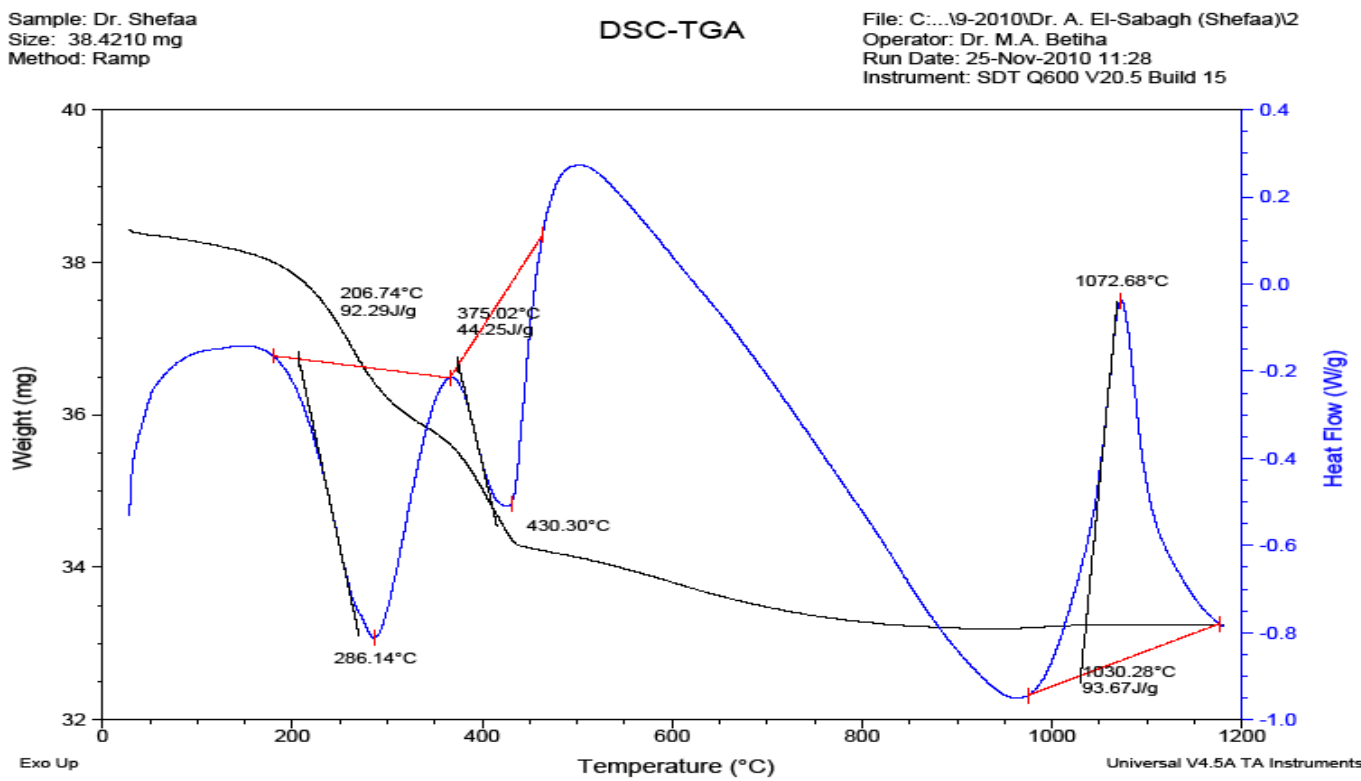

Figure 2-7:- DSC and TGA analysis of scolecite zeolite. 


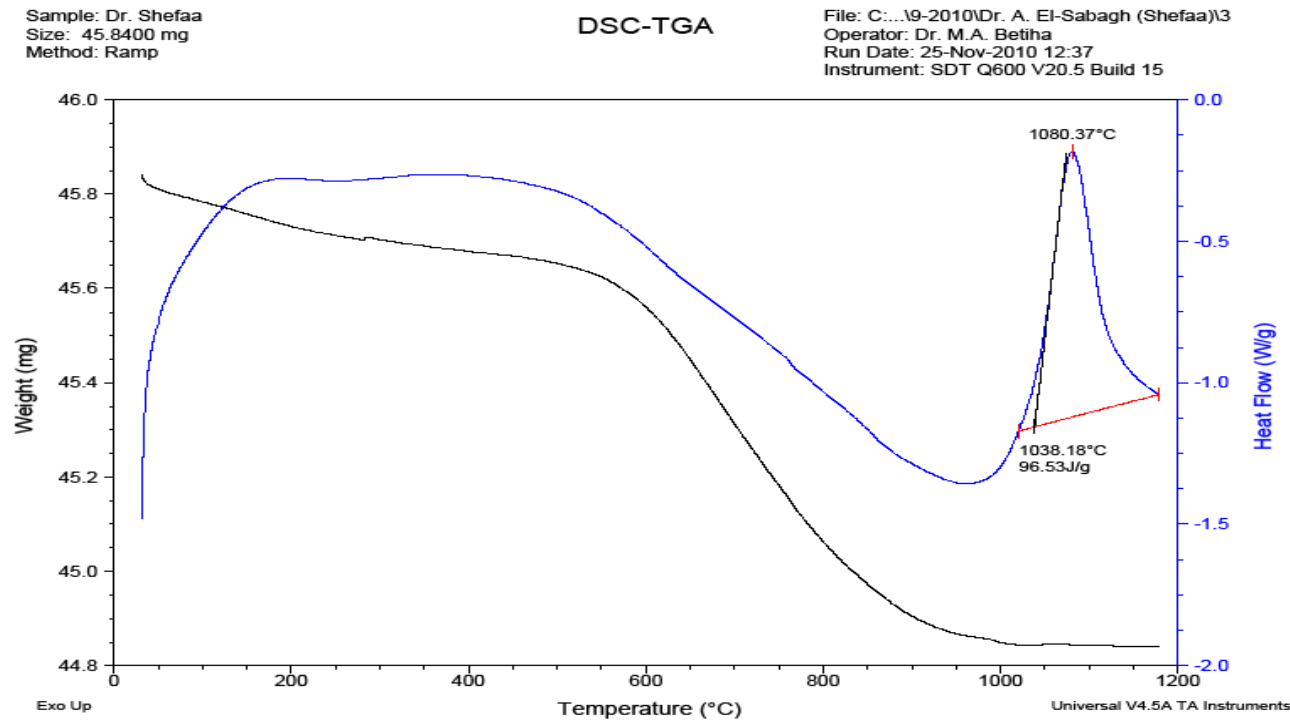

Figure 2-8:- shows DSC and TGA analysis of H/ scolecite zeolite(zeolite treated with ammonium)

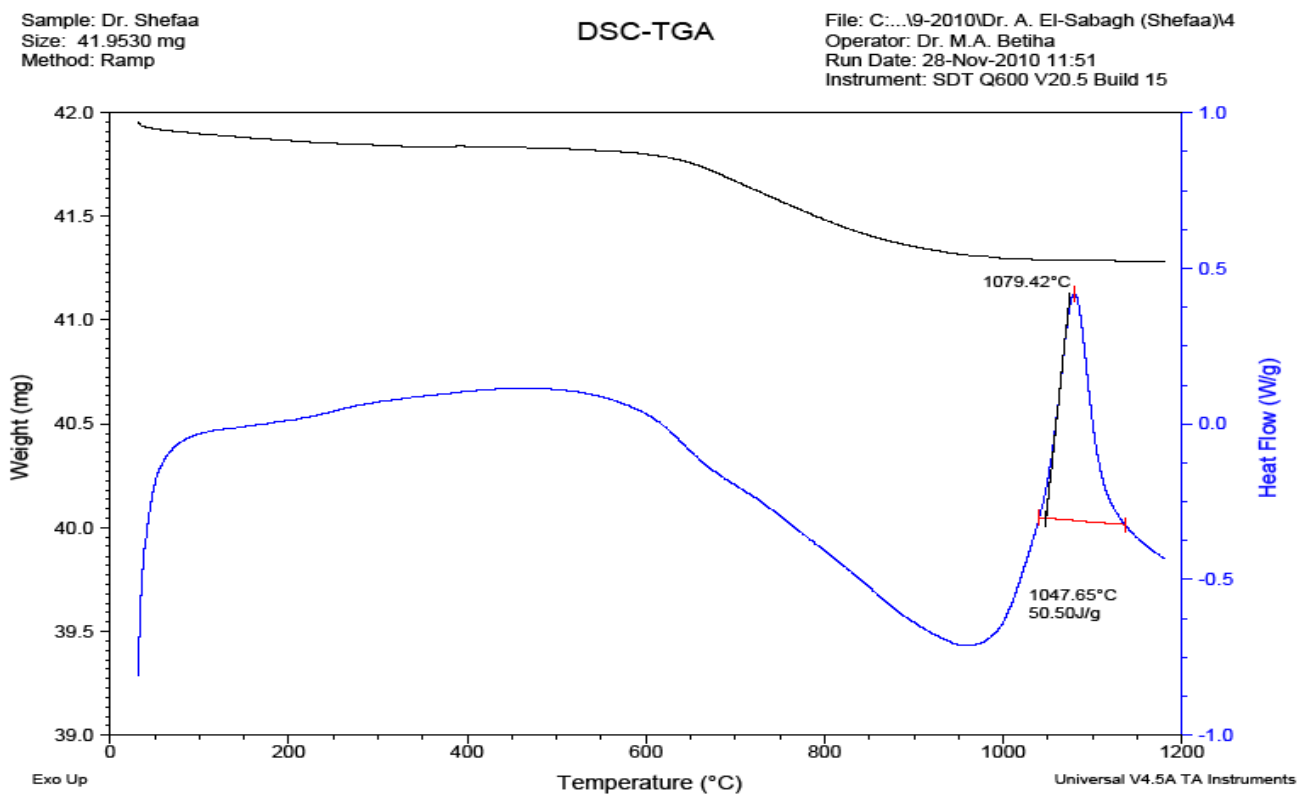

Figure 2-9 DSC and TGA analysis of $\mathrm{Pt} / \mathrm{H} /$ scolecite zeolite.

\section{Characterization of Zeolite (y):-}

TPR analysis of zeolite $Y$ :-

figures (2-10), (2-11) below show result of TPR of zeolite $\mathrm{Y}$, zeolite $\mathrm{Y}$ treated with ammonia ( $\mathrm{H} / \mathrm{Y})$ and zeolite $(\mathrm{Pt} / \mathrm{H} / \mathrm{Y})$ treated with $\mathrm{H}_{2} \mathrm{PtCl}_{6}$.

Evidently the thermal stability of zeolite was enhanced after treatment with Pt . 


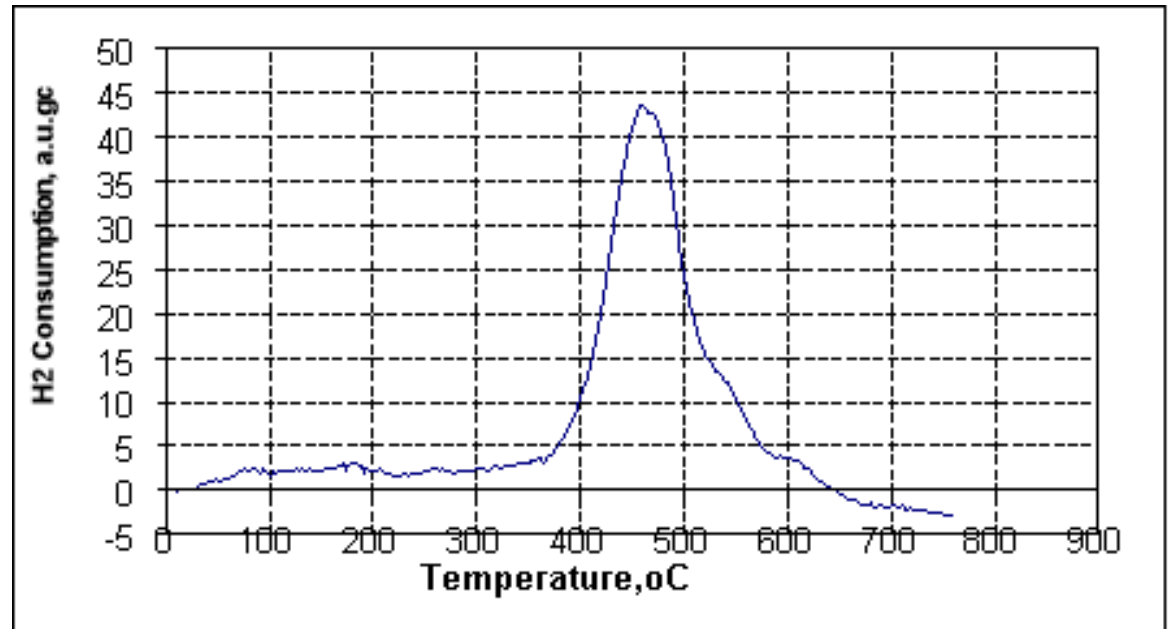

Figure (3-10) TPR analysis of $H / Y$

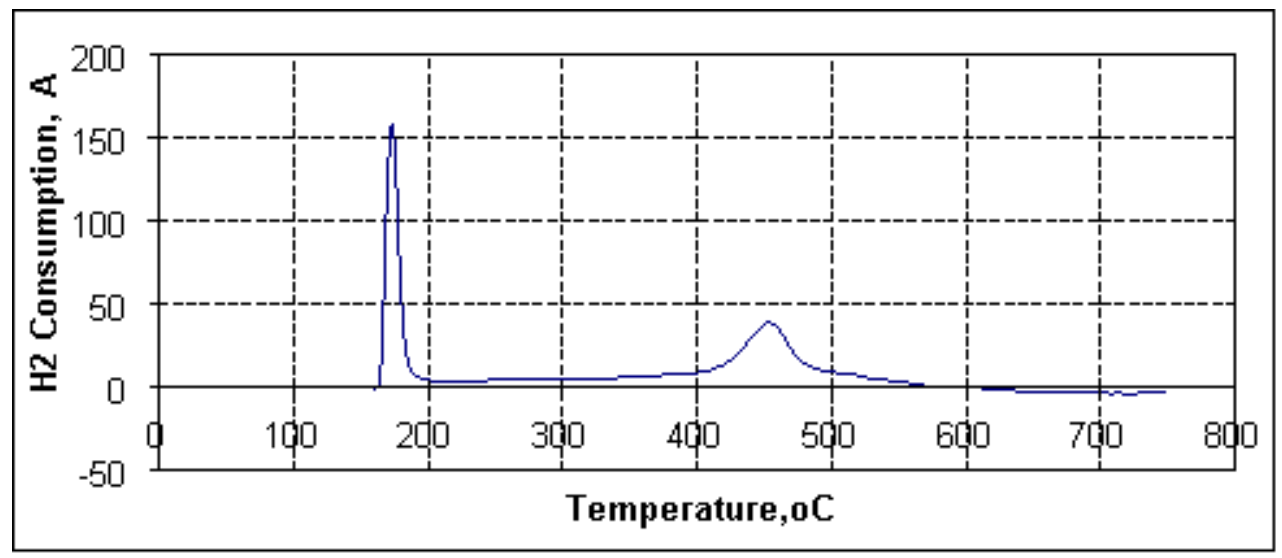

Figure(3-11) TPR analysis of Pt/H/Y

DSC and TGA analysis of zeolite Y:-

Figures( 2-12, (2-13) and (2-14) Show plots of thermal analysis of zeolite $\mathrm{Y}$, zeolite H/Y treated with ammonia and zeolite $\mathrm{H} / \mathrm{Y}$ treated with $\mathrm{H}_{2} \mathrm{PtCl}_{6}$ by differential scanning calorimetry and thermogravimetric analysis respectively. The tepreature DCS of zeolite Y was increased in zeolite after treatment with ammonium , and Pt . these results illustrated the enhance of thermal stability of zeolite $\mathrm{Y}$. 


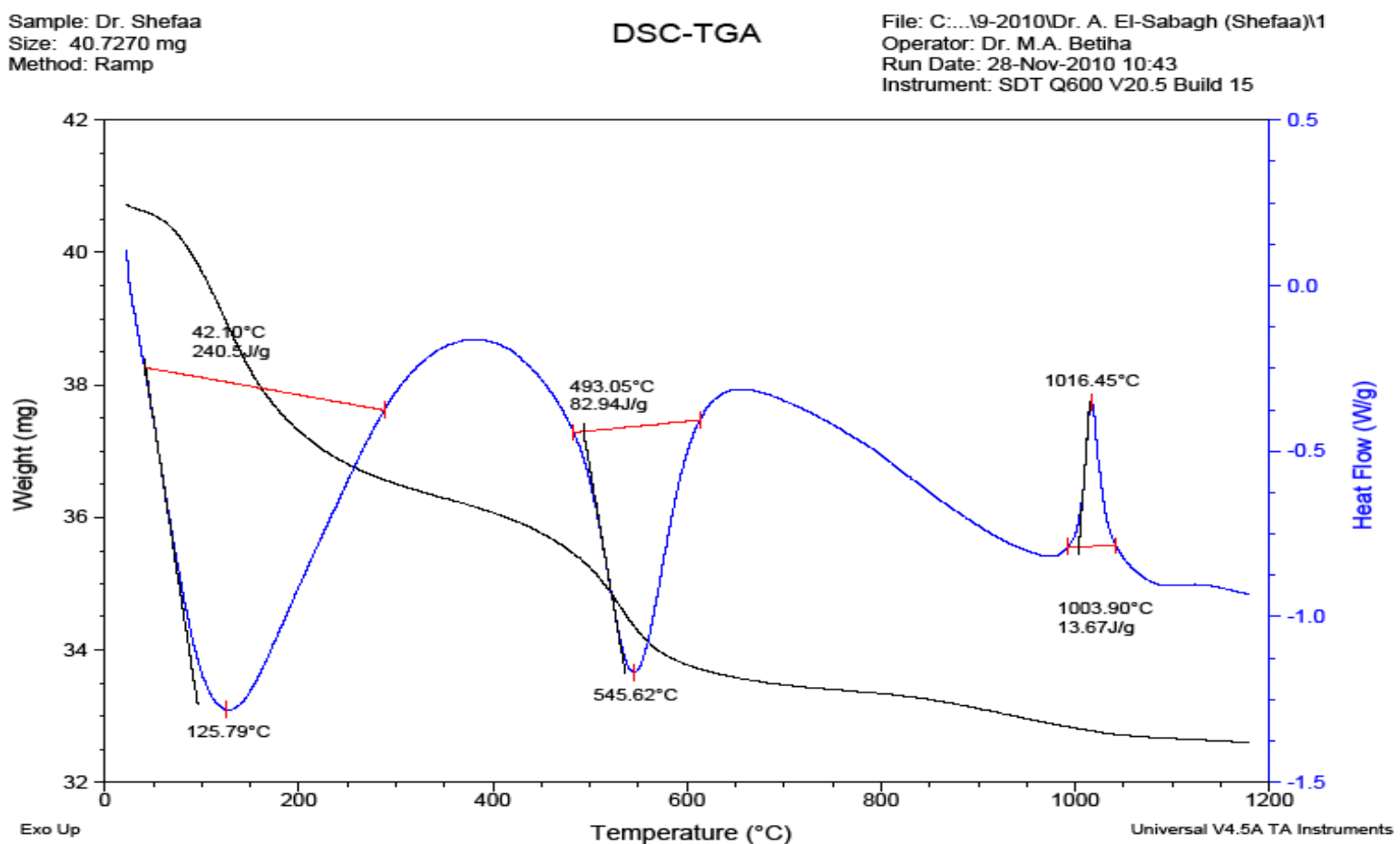

Figure 2-12:- DSC Analaysis of Zeolite Y.

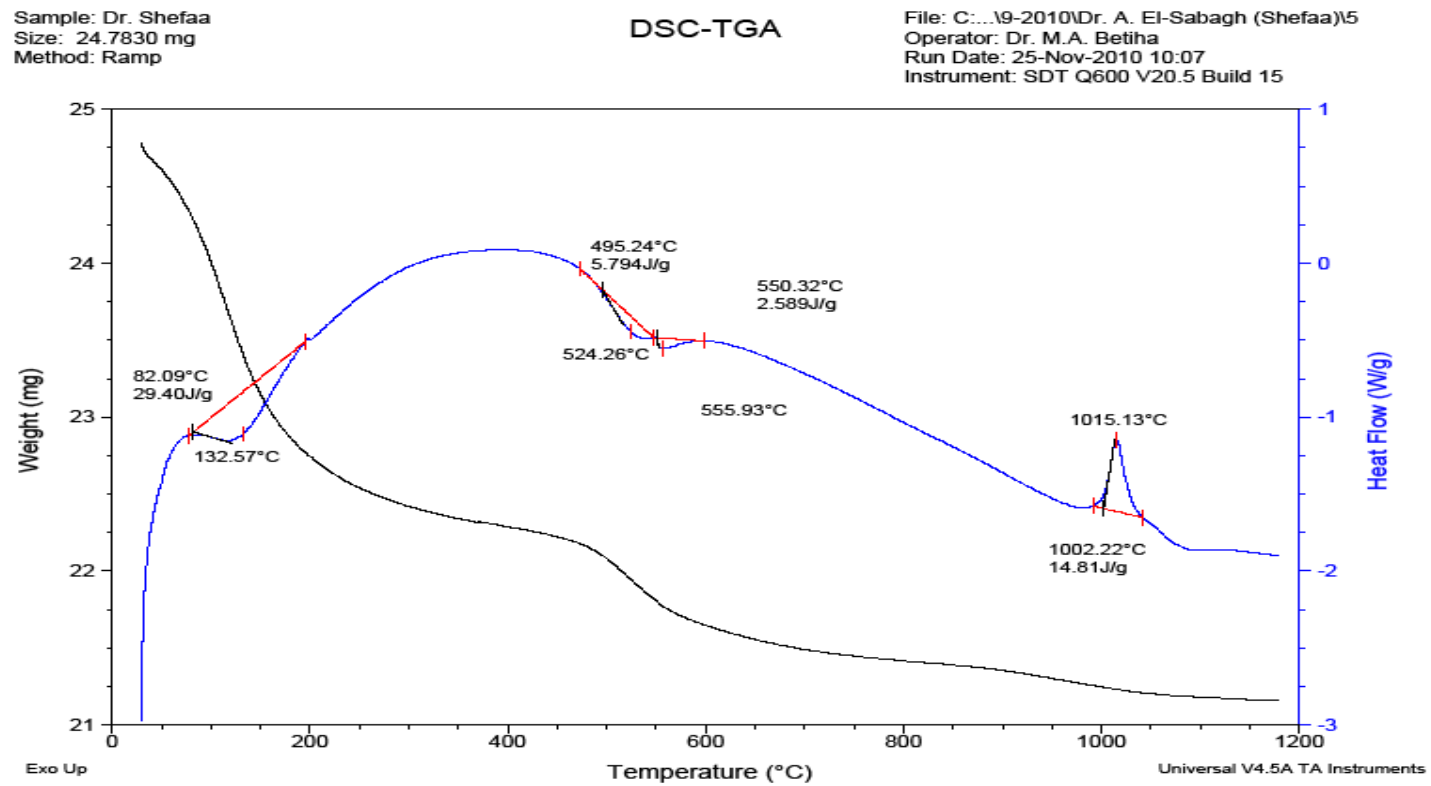

Figure 2-13:- DSC Analaysis of Zeolite H/Y. 


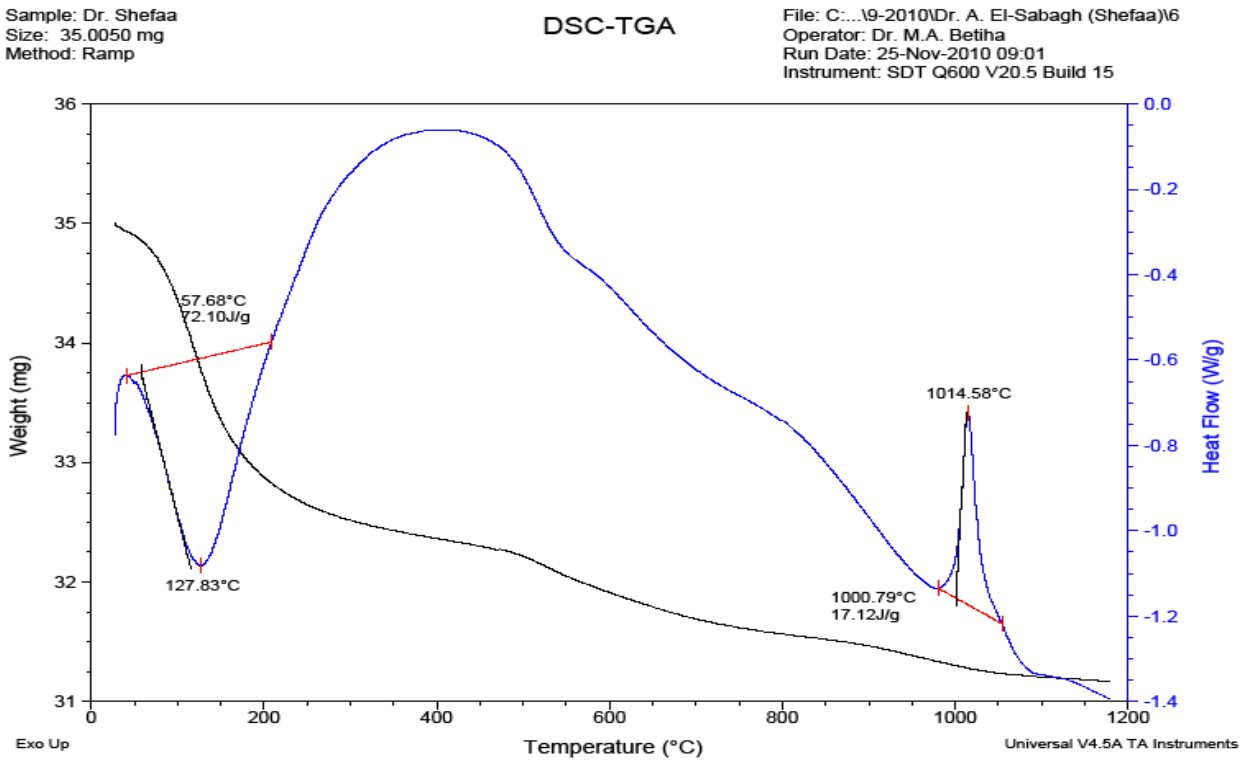

Figure 2-14:- DSC Analysis of Zeolite $\mathrm{Pt} / \mathrm{H} / \mathrm{Y}$.

\section{Surface area of zeolite $\mathrm{Y}$ :-}

Figure (2-11), (2-12) and (2-13) show plots of surface area of zeolite $\mathrm{Y}$, zeolite $\mathrm{Y}$ treated with ammonia and zeolite $\mathrm{Y}$ treated with platinum hydrochloride respectively. Figure (3-46) gave the surface area of 350, while the surface area of zeolite after treated with ammonia and Pt increased to 340 and 370 respectively

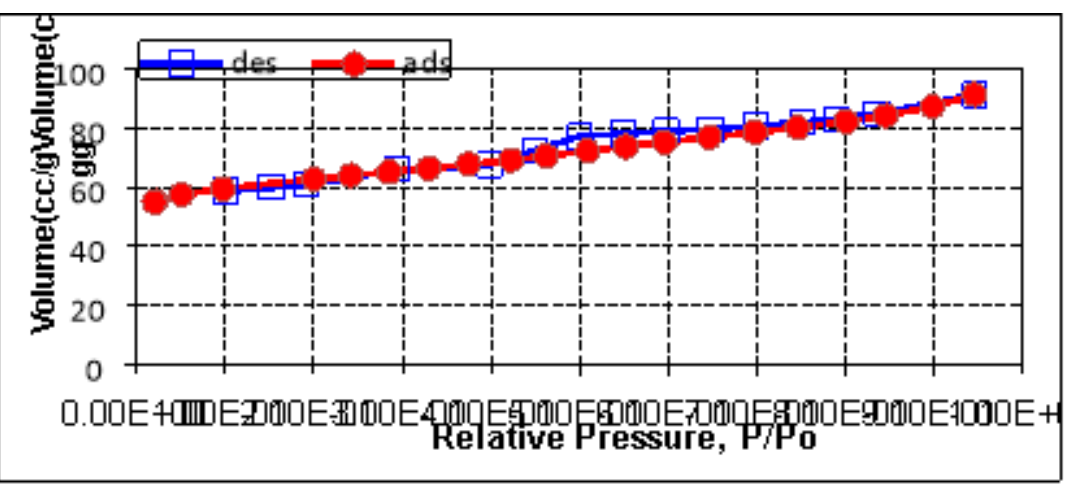

Figure (2-15) Surface area of zeolite (Y)

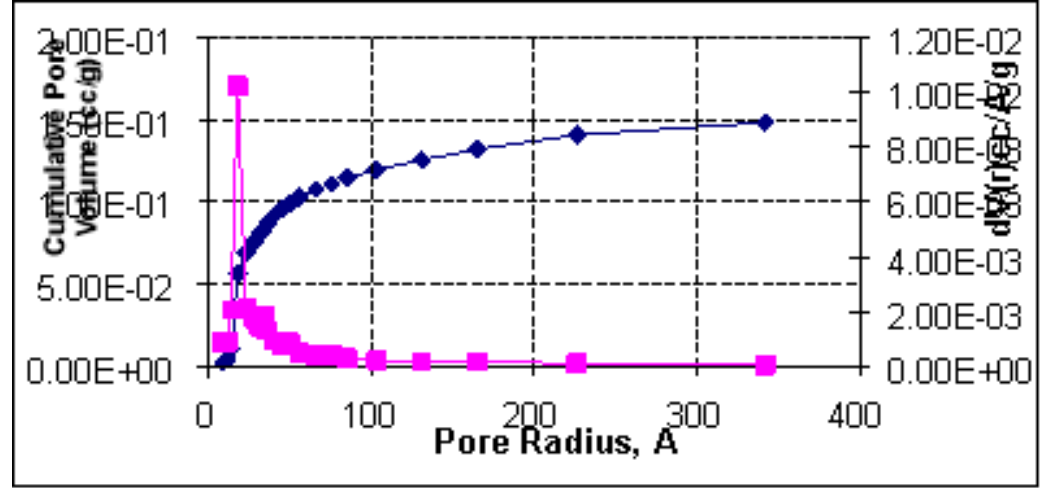


Figure (2-16) Surface area of zeolite (H/Y)

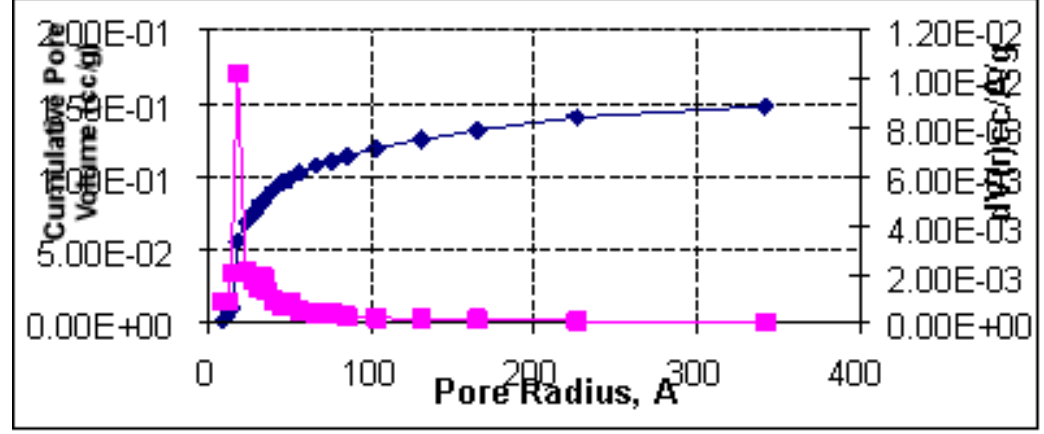

Figure (2-17) Surface area of zeolite (Pt/H/Y)

\section{Conclusion and Recommendation:-}

Zeolite are stable, nontoxic and preventing contamination of valuable feed stock's .Zeolite is used as heterogeneous catalyst due to stability to cavity, its thermal at high temperature and secretive even at unfavorable reactant ratio and the reaction is eco-friendly . Natural zeolites are having intercalated water molecules however after treatment of zeolite these molecules are removed and cavity which is responsible to the activity of zeolite.

The study identify the main characteristics of zeolite $Y$ and scolecite and the results show the most important of these types of zeolite in industrial uses. The researcher characterization after modification and it get suitable results. The researcher recommended that to continue this study to do more purification of natural zeolite .

Use of zeolite $s$ as a catalyst in the manufacture of some fine chemicals should expand .New zeolite catalysts should be developed with improved application selectivity and new functionalities,perhaps for strong base and oxidation catalysis . New ion exchange of new micro porous oxide also may be expected. Experience has taught that the availability of new materials normally precedes by many years the discovery of all of their useful properties and the conception and development of new uses. The research should be continue in the purification and modification of natural zeolite to be useful in many applications . Because its economic and cheap

\section{The references :}

1. Satterfield, C., N., "Hetrogenous catalysis in industrial practice", Mc graw-Hill, (1991).

2. Deer, Howie \& Zussman, w. A . Dear F.R.S, Emeritus professor of mineralogy \& petrology, Introduction to the rock forming minerals, university of Cambride R.A. Howie professor of mineralogy, king's college. University of London, J.Zuss man professor of Geology, University of Manchester (1966).

3. Lead as gasoline additive, www.sp.uconn,edu/-geo $101 \mathrm{vc/lecture} 25 /$ tsld $011 . \mathrm{html}$.

4. Mohsen Manutchehr - Danai, Dictionary of Gems and Gemology springer .verlag berlin Heidelberg New york 2009, 10. 1007 / $978-3-540-72816-0$ - 15021.

5. R.M.BARRER,FRS, Zeolites and Clay minerals as sorbents and molecular sieves, Chemistry department ,imperial college ,London.

6. H.W langmi ,D.book Hydrogen storage in ion-exchanged zeolites, A.walton,,S.R.Johnson,M.M.Al.Mamouri,.Speight,P.P.Edwards,I.R.

7. JENNIFERL ANTHONY and marke DAVis, Assembly of Zeolites and Crystalline molecular sieves California institute of technology ,Chemical engineering , Pasadena ,CA91125 (P N 159).

8.

Shujiang yang ; Mohammed lach -hab ,losifI .vaisman, and Estela

Blaisten-Barojas, Achem in formatic Approach for zeolite frame work determination ,computational material science center George mason University MSN6A2, fairfax ,Virginia 2203 ,USA department of computation 
and data science Geroge Mason university ,MSN 6A2 Fairfax Virginia 22030 ,USA BLAISTEN@ GMU.EDU (ppn 160-161) (2009).

9. Carlos Alberto Rios Reyes, Doctoral thesis synthesis of zeolites from geological materials and industrial wastes for potential application in environmental problems (2008).

10. A.Andziulis, Naphtha pool of commercial Gasoline and NiR -spectrum pattern, Klaipeda university PPN202 (2001).

11. Breck, D., W., "Zeolite Molecular Sieves" wiley. Interscience publication, (1974).

12, Jens wietkamp * Zeolites and catalysis, institute of chemical technology , university of Stuttgart ,D- 70550 Stuttgart ,Germany received solid state lonics 131 (2000) 175-188.

13.. P.H. Desai ,D.A. key worth ,M.x. Asin and T.reid,Akzoc Enhance gasoline yield and quality selecting the might hydro treating catalyst for FCC pretreatment can lead to higher HDS ,HDN and aromatics saturation activity, chemical Inc ,Pasadena ,Texas, and A.H.Pichel ,Akzo chemical Inc .,The Netherlands PPN(106).

14, Use DONALDW. Breck Senior Research fellow , union carbide corporation ,Tarrytown ,newyork ,awiley interscience publication ,NewYork . London . Sydney Toronto ppn N 445 - 459, (1974).

15 atomic net charges determination a natural zeolite theScolecite

\section{SANDERINEKUNTZINGER,NOUREDDINEGHERMANI,CLAUDELCOMTECOMTE and}

YVESDUAUSOY Universite Henri Poincare ,Nacy ,Faculte des science, Boulevard des Aiguillettes ,BP239,54506 vandoeuvre -les- Nancy cedex,frace (2000).

16 Baerlocher ch, mccusker LB,Olson DH(2007)Atlas of zeolite framework, types ,bth edn, Elsevier, Amsterdam.

17 . Roberto Millini carlo perego, The Role of Molecular Mechanic and Dynamic Method in Development of zeolitse catalytic processes, published online :30 January 2009 @ s springer science + business media ,LLC (2009) .PPN (43-49).

18 . htt://en.wikipedia.org/wiki/wikipedia: text of creative commons Attribution-shape Alike-3.0-unported-license 24march (2010).

19 - Martin wallau and U,F Schuchardt, Catalysis by metal containing zeolites: basic site, Institute Quimica ,Universidade Estadual de Campinas, C.P.6154 ,13083 - 970 campinassp ,Brazil ,Received :march24,1995,june 20,1995 (PPN 394-395).

20 - J.N.H.Reek, P.W.N.M. VAN leewen, A.J.G.J . VAN Der HAM and A.B.DEHAAN, supported catalyst immobilization of tailor - made Homogeneous catalysts ., University of Amsterdam ,van,t Hoff institute for molecular sciences , Neuwe Achtergracht 166,1018 wv, Amsterdam, the Netherlands, Separation technology group faculty of science and technology university of TwentePo Box 217, 7500 AE Enscheae, the Netherlands PPN (39-40) (2006).

21 - M.M. Rahman, N. Hasnida , and W.B. Wan Nik, preparation of zeolite y using local Raw material Rice Husk as a silica source, pharmaceutical chemistry, Faculty of pharmacy, international Islamic university of Malaysia , maritime technology department, faculty of maritime studies and marine science, university Malaysia .5 February (2009). 
22 - probes x vonne Tara .Sarah Sealy .Jenswt kamp Characterization of the pore size of molecular sieves using molecular, institute of chemical technology, university of Stuttgart, 70550 Stuttgart ,Germany jens WEITKAMP@ITC.UNI-STUTTGART de,mol sieves (2007).

23 - A line A uroux, Acidity and Basicity :determination by adsorption micro calorimetry, Institute de Recherches surla catalyze, CNRS ,2avenue Einstein ,69626 Vileurbanne cedex ,france a line .auroux@catalyse.cnrs .fr mol sieves (2008) 6:45-52 .

24 - Yvonne Traa.Sarah sealy. Jens weitkamp Characterization of the pore size of molecular ,sieves using molecular probes, Institute of chemical technology ,university of Stuttgart ,70550 Stuttgart ,Germany jens . WEITKAMP@ITC.UNI.STUTTGART, de, mole sieves 5:103 - 154 PPN (141 - 142)(2007).

25 - Devid Tin win .Sinfelt, J.H., Zeolites - earliest solid state acids, "Role of surface science in catalysis". Surface science, 500, 923-946. (2002).

26 William M.Shirley and S.P.Scoville Transition metal complexes supported on zeolites, diffusive flectance frared and temperature -programmed decomposition studies of (benzene) tricarbnyl chromium (0) on Nax zeolite "micro porous and mesoporous material,37(2000) 271.

27 - V .Shinde .womanrao N.Jadhar .machindrak . lande. Laxman S, Gadekar .Balasaheb R.Arbad . Jeevan M.kondre - Scolcite as a Novel Heterogeneous acid catalyst for an Efficient synthesis of 3,4 dihydropyrimidin -2 $(1 \mathrm{H})$-ones via multi component Biginelli Reaction Sndeep, Received :25 February 2008 /accepted :2 may 2008 /published online 28 may 2008 . @ springer science business media-LLC 2008 - ppN 59).

28 - V.V,Bakakin and Yu.V.Seryotkin . A.V.Nikolaev ,Unified formula and volume characteristics in comparative crystal chemistry of Natural zeolites, institute of inorganic chemistry ,Siberian Division, Russian Academy of sciences, Novosibirsk; BAKAKIN@CHE.NSK.SU.V.S.SOBOLEV institute of Geology and mineralogy ,Siberian Division, Russian Academy of Sciences, Novosibirsk translated from Zhurnal strukturnoi khimii,vol.50,supplement,pp.s 123.s130,2009. Origenal article submitted march 2,2008.

29 - Naccahe, C., and Taarit, Y., B., "Transition metal exchanged zeolites: physical and catalytic properties", zeolite: science and technology, 80,373-396,(1984).

30 - H.Van bekkum, Studies in surface science and catalysis introduction to zeolite science and practice ,Laboratory of organic chemistry, Applied Chemistry Department ,Delft, university of technology „Julianalaan 136 , 2628 Bl Delft, the Netherlands ,E.M.Flanigen Uop, Tarrytown Technical Center , Research and Molecular sieves Technology, Tarrytown NY10591,U.S.A, J.C.Jansen, Laboratory of organic chemistry department delft, university of technology ,julianalaan 136, 2628 bl delft , the Netherlands ,Elsevier Amsterdam -oxford - newyork - Tokyo (1991). 